Research article Open Access

\title{
Expression of 5-lipoxygenase and 15-lipoxygenase in rheumatoid arthritis synovium and effects of intraarticular glucocorticoids
}

\author{
Karina Roxana Gheorghe ${ }^{1,2}$, Marina Korotkova², Anca Irinel Catrina², Linda Backman³ , Erik af Klint ${ }^{2}$, \\ Hans-Erik Claesson 3,4 , Olof Rådmark ${ }^{4}$ and Per-Johan Jakobsson 2,5
}

\author{
1Department of Biosciences and Nutrition, Novum, Karolinska Institute, SE-141 57 Huddinge, Sweden \\ ${ }^{2}$ Department of Medicine, Rheumatology Unit, Karolinska University Hospital and Karolinska Institute, S-171 76 Stockholm, Sweden \\ ${ }^{3}$ Orexo AB, Virdings allé 32 A, SE-751 05 Uppsala, Sweden \\ 4Department of Medical Biochemistry and Biophysics, Karolinska Institutet, SE-171 77 Stockholm, Sweden \\ ${ }^{5}$ Karolinska Biomic Center, Karolinska University Hospital and Karolinska Institute, S-171 76 Stockholm, Sweden \\ Corresponding author: Per-Johan Jakobsson, Per-Johan.Jakobsson@ki.se
}

Received: 6 Jan 2009 Revisions requested: 24 Feb 2009 Revisions received: 6 May 2009 Accepted: 4 Jun 2009 Published: 4 Jun 2009

Arthritis Research \& Therapy 2009, 11:R83 (doi:10.1186/ar2717)

This article is online at: http://arthritis-research.com/content/11/3/R83

(c) 2009 Gheorghe et al.; licensee BioMed Central Ltd.

This is an open access article distributed under the terms of the Creative Commons Attribution License (http://creativecommons.org/licenses/by/2.0), which permits unrestricted use, distribution, and reproduction in any medium, provided the original work is properly cited.

\begin{abstract}
Introduction It was previously shown that lipoxygenase (LO) pathways are important in the rheumatoid arthritis (RA) inflammatory process and that synovial fluid from RA patients contains high amounts of leukotrienes. We therefore aimed to investigate the 5-LO and 15-LO-1 expression pattern in RA and ostheoarthritis (OA) synovial tissue and to study the effect of intraarticular glucocorticoid (GC) therapy on enzyme expression.

Methods Expression of LOs was evaluated by immunohistochemistry in RA and OA synovial biopsies. Cellular localization of these enzymes was analyzed by double immunofluorescence. In synovial biopsies from 11 RA patients, 5-LO and 15-LO-1 expression was evaluated before and after triamcinolone hexacetonide knee injection and assessed by image analysis to quantify their expression. We also investigated the presence of 15-LO-1 by immunohistochemistry in synovial fluid (SF) cells as well as their ability to form 15-
\end{abstract}

hydroxyeicosatetraenoic acid (15-HETE) following treatment with arachidonic acid (AA).

Results 5-LO and 15-LO-1 are present in RA and OA synovium, with 5-LO being mostly expressed in lining and sublining macrophages, neutrophils and mast cells and 15-LO-1 mainly in lining macrophages, fibroblasts and sublining endothelial cells. Intraarticular GC treatment resulted in a significant suppression of 5-LO expression, but did not influence the 15-LO-1 enzyme significantly. Also, SF cells express a functional 15-LO-1 and produce 15-HETE when challenged with AA.

Conclusions These data demonstrate that local therapy with GC decreases 5-LO expression in RA synovium and offer an additional possible mechanism for the efficiency of intraarticular adjuvant therapy in RA.

\section{Introduction}

Rheumatoid arthritis (RA) is a chronic inflammatory disease characterized by polyarticular joint inflammation, synovial hyperplasia, and cartilage and bone destruction, with subsequent joint deformities. The inflammatory synovial fluid in RA patients contains-in addition to various cytokines and growth factors-high levels of leukotrienes, with leukotriene $B_{4}\left(\mathrm{LTB}_{4}\right)$ being predominant [1].
$\mathrm{LTB}_{4}$ is a powerful proinflammatory lipid mediator and one of the most potent chemotactic agents known to date [2]. This leukotriene is produced mainly by neutrophils, macrophages and mast cells, and promotes neutrophil recruitment and activation [3]. Neutrophils are the most abundant leukocytes in rheumatoid joints [4], and have destructive potential by secreting proteases and reactive oxygen species and by promoting synthesis of matrix metalloproteinases $[5,6]$. Several lines of evidence have implicated $\mathrm{LTB}_{4}$ as an important mediator of joint inflammation in RA. $\mathrm{LTB}_{4}$ is present at higher levels in

15-HETE: 15-hydroxyeicosatetraenoic acid; AA: arachidonic acid; GC: glucocorticoid; IL: interleukin; LO: lipoxygenase; LTB $_{4}$ : leukotriene $\mathrm{B}_{4}$; OA: osteoarthritis; PBS: phosphate-buffered saline; RA: rheumatoid arthritis; RANKL: receptor activator of NF-кB ligand; TNF: tumor necrosis factor. 
serum of patients with active RA compared with patients with inactive arthritis or normal subjects [7], and its levels correlate with the disease severity [8].

A critical contribution of neutrophil-derived $\mathrm{LTB}_{4}$ to arthritis induction and severity has recently been revealed in a mouse serum transfer model of inflammatory arthritis [9]. In this study it was shown that mice lacking 5-lipoxygenase (5-LO) or leukotriene $\mathrm{A}_{4}$ hydrolase enzymes are protected from developing the disease and that there is a specific requirement for $\mathrm{LTB}_{4}$ and not other leukotrienes for the pathogenesis in this model. 5-LO and 5-LO activating protein (FLAP), followed by leukotriene $A_{4}$ hydrolase, are the enzymes responsible for the sequential formation of $\mathrm{LTB}_{4}$ from arachidonic acid (AA).

15-Lipoxygenase (15-LO) is a lipid-peroxidizing enzyme mainly expressed in airway epithelial cells, eosinophils, reticulocytes and macrophages. In humans, 15-LO exists as two different enzymes with different cell localizations and product profiles [10]. 15-LO-1 converts AA to an unstable intermediate, 15hydroperoxyeicosatetraenoic acid, which can be further converted to 15-hydroxyeicosatetraenoic acid (15-HETE). The 15LO-1 enzyme has proinflammatory actions, with high levels of 15-HETE reported in sputum of asthmatic patients along with increased macrophage 15-LO-1 mRNA expression [11]. 15LO-1 expression is induced by IL-13 in human blood monocytes [12] and by IL-4 in monocytes, alveolar macrophages, dendritic cells, mast cells and rheumatoid arthritis synovial cells [12-18]. Only recently was it reported that 15-LO-1 can catalyze the metabolism of AA to the proinflammatory eoxins that can increase permeability of the endothelial cell monolayer in vitro, indicating that they can enhance vascular permeability [19]. 15-LO-1 products, however, were also demonstrated to have protective roles in inflammatory disorders due to formation of anti-inflammatory lipoxins [20-22]. The 15-LO-1 mRNA was demonstrated to be present in RA synovial membranes [23] and its expression was stronger in RA compared with osteoarthritis (OA) biopsies [24].

The 5-LO cascade and the role of $\mathrm{LTB}_{4}$ in RA are well documented. Although the presence of 5-LO enzyme in the synovial lining of rheumatoid tissue has recently been reported [24], a detailed characterization of cells expressing 5-LO in human synovial tissue is lacking. Evidence is also limited regarding the influence of current therapy for RA on this pathway.

Glucocorticoids (GCs) are used in RA as an efficient adjuvant therapy and their efficacy is related to their broad anti-inflammatory profile, with inhibition of inflammatory cells functions [25]. Controversial results have been reported about the effects of GCs on 5-LO expression and $\mathrm{LTB}_{4}$ formation. Some studies reported that 5-LO pathway activity is decreased in the presence of GCs $[26,27]$, while other investigators have shown that in vivo GC administration had no influence on $\mathrm{LTB}_{4}$ formation $[28,29]$. In contrast, leukotriene synthesis and
5-LO expression were increased in human blood monocytes [30] and mast cells [31] by dexamethasone. In addition, blood polymorphonuclear neutrophils from RA patients released higher amounts of $\mathrm{LTB}_{4}$ after GC pulse therapy [32] while intraarticular corticosteroids reduced the $\mathrm{LTB}_{4}$ level in synovial fluid of RA patients [33].

In comparison, there are few studies to date investigating the effects of corticosteroids on 15-LO-1 expression. In a rabbit model for atherosclerosis, corticosteroid treatment was shown to decrease atherosclerotic plaque formation along with increasing 15-LO-1 expression in the arterial wall [34]. GC treatment of asthma patients, however, has been reported to decrease the expression of 15-LO-1 in the lung [35].

In the present study we characterized the expression pattern of 5-LO and 15-LO-1 enzymes in synovial tissue of RA and OA patients and phenotyped the positive cells. In addition, we determined the effects of intraarticular glucocorticoids on the expression of these enzymes in RA synovium.

\section{Materials and methods \\ Patients}

In the first study group, we analyzed synovial biopsies from six RA patients and from five OA patients collected at the time of orthopedic surgery. In a second group, 11 RA patients were recruited into the study. The demographical and clinical data of the second patients group are presented in Table 1.

All patients in the second group received an intraarticular knee injection of $40 \mathrm{mg}$ triamcinolone hexacetonide, and synovial biopsies were collected by arthroscopy immediately prior to treatment and a median of 10 days after treatment. The treatment regimen remained unchanged from at least 2 weeks prior to and during the entire study period.

\section{Table 1}

Demographical and clinical data of the second patient group ( $n$ =11)

\begin{tabular}{ll}
\hline Characteristic & Value \\
\hline Age (years) & 68 (35 to 83$)$ \\
Gender (male/female) & $3 / 8$ \\
Disease duration (months) & 24 (3 to 240$)$ \\
Current knee arthritis episode duration (months) & 2 (0.5 to 6$)$ \\
Taking disease-modifying antirheumatic drugs & 6 \\
Taking oral corticosteroids & 2 \\
Taking nonsteroidal anti-inflammatory drugs & 4 \\
Time between biopsies (days) & $10(7$ to 12) \\
\hline
\end{tabular}

Data presented as median (range) or number of patients. 
All RA patients fulfilled the 1987 American College of Rheumatology diagnostic criteria for RA [36]. The ethics committee at the Karolinska Hospital approved all experiments on human cells and tissues. Informed consent was obtained from all study subjects.

\section{Tissue preparation and immunohistochemical analysis}

Serial cryostat sections $(7 \mu \mathrm{m})$ were fixed for 20 minutes in $2 \%$ formaldehyde $(\mathrm{v} / \mathrm{v})$, air-dried and then stored at $-70^{\circ} \mathrm{C}$. Immunohistochemical staining was performed as described previously [37]. The inhouse antibodies used were affinity-purified rabbit polyclonal antibody against human 5-LO and rabbit polyclonal anti-human 15-LO-1 antibody. Rabbit lgG served as the negative control. Stained synovial biopsies were evaluated using a Polyvar II microscope (Reichert-Jung, Vienna, Austria) and photographs were taken with a digital camera (300F; Leica, Cambridge, UK). Synovial expression of 5-LO and 15LO-1 was quantified by computer-assisted image analysis and was expressed as the percentage of positive stained area versus total tissue area.

Synovial fluid cells from RA patients were collected on slides by cytospin centrifugation. The slides were then fixed and processed for immunhistochemical detection of 15-LO-1 as described above.

\section{Immunofluorescence staining}

Double immunofluorescence staining was performed using rabbit anti-human 5-LO or 15-LO-1, mouse anti-human CD163 (Ber-MAC3; DakoCytomation, Glostrup, Denmark), mouse anti-human CD68 (KP1; DakoCytomation), mouse antihuman prolyl 4-hydrolase (DakoCytomation), mouse antihuman CD66b (80H3; Beckman Coulter, France), mouse antihuman CD3 (SK7; BD Biosciences, San Jose, CA, USA), mouse anti-human CD20 (DakoCytomation), mouse antihuman CD31 (EN4; Novakemi AB, Handen, Sweden), and mouse anti-human mast cell tryptase (Chemicon International, Temecula, CA, USA) antibodies.

The staining procedure has been published previously [38]. Briefly, after blocking with an avidin-biotin kit (Vector Laboratories, Peterborough, UK), sections were incubated overnight with primary antibodies. Subsequently, slides were incubated with secondary biotinylated goat anti-rabbit antibody (heavy and light chain; Vector Laboratories) and streptavidin-conjugated fluorochrome Alexa 488 (Molecular Probes, Leiden, the Netherlands). The slides were blocked again with the avidinbiotin kit and were incubated with the next secondary biotinylated horse anti-mouse antibody (IgG heavy and light chain; Vector Laboratories), followed by streptavidin-conjugated fluorochrome Alexa 546 (Molecular Probes). Matched IgG isotype controls were included for all markers.
15-LO-1 product measurement in RA synovial fluid cells Synovial fluid from RA patients was centrifuged and the pelleted cells were resuspended in PBS and washed twice. The cellular composition of synovial fluid cells was analyzed using flow cytometry. Monocyte, neutrophil and lymphocyte populations were identified using a FACSCalibur (Becton Dickinson, San Jose, CA, USA) and Cell Quest software (Becton Dickinson). AA was added to a final concentration of $40 \mu \mathrm{M}$ and the cells were incubated for 5 minutes at $37^{\circ} \mathrm{C}$. Buffer control without cells was used to assess for spontaneous degradation of AA. Subsequently, the samples were centrifuged and the supernatant collected and stored at $-70^{\circ} \mathrm{C}$ until analysis by enzyme immunoassay according to the manufacturer's instructions (Cayman Chemicals, Ann Arbor, MI, USA).

\section{Statistical analysis}

Statistical analysis was performed using the Wilcoxon test and Bonferroni correction for multiple comparisons for paired samples for the synovial biopsy data, and using the Mann-Whitney test for 15-HETE production.

\section{Results \\ RA synovial tissue displays a higher expression of 5-LO and 15-LO-1 enzymes compared with OA samples}

We detected intracellular 5-LO staining in all RA samples studied. Sections incubated with the preadsorbed 5-LO antibody showed no significant staining, confirming the specificity of the antibody for the 5-LO enzyme (Figure 1a, inset). Strong 5 -LO staining was shown in macrophage-like cells within the synovial lining layer and in sublining tissue (Figure 1a,b). 5-LO positivity was scarce in the follicular mononuclear infiltrates, with the majority of patients not having detectable staining in these areas. By contrast, 15-LO-1 showed a very strong staining pattern mainly in the synovial lining cells and in vessels, with lower expression in scattered sublining macrophage-like and fibroblast-like cells (Figure 1e). The specificity of 15-LO-1 antibody was tested in bronchial tissue, and the airway epithelium was strongly stained (Figure 1d). In contrast, there was no staining after preincubation with the 15-LO-1-specific peptide against which the antibody was raised (Figure 1d, inset).

The OA synovial samples displayed mostly large areas of fibrosis and cartilage, with limited synovial membranes. Positive staining for 5-LO and 15-LO was detected almost exclusively in the synovial membrane areas. OA tissue showed low expression of both 5-LO and 15-LO-1 enzymes, with few stained cells scattered in the synovial membrane areas (Figure 1c,f). Strong staining for 15-LO-1, however, was detected in blood vessel cells.

We then quantitatively analyzed the expression of LO enzymes in RA and OA synovial tissue sections. Both 5-LO and 15-LO1 showed a lower expression in OA synovial tissue compared with RA samples (Figure 2). 

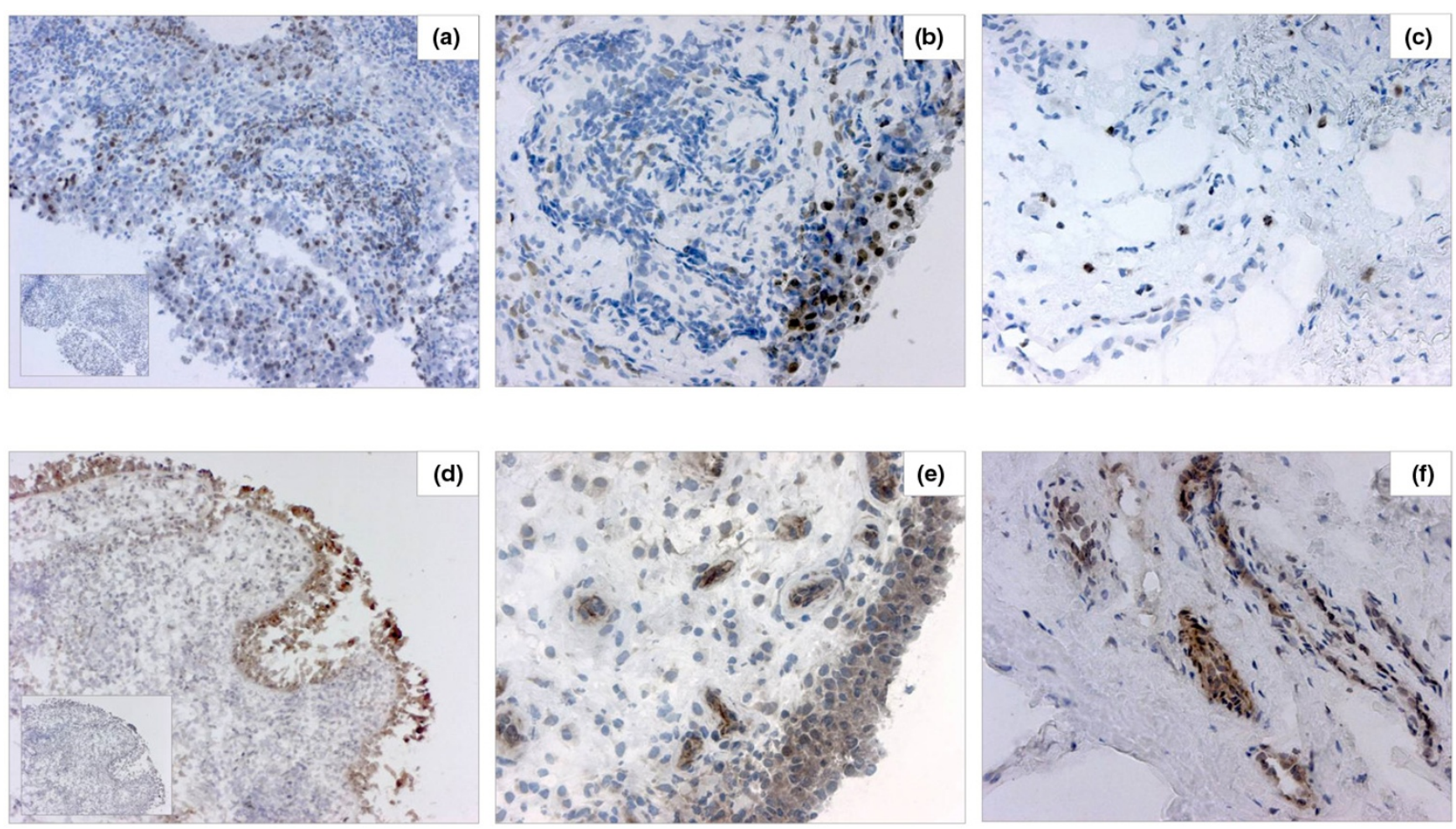

Lipoxygenase enzymes in rheumatoid arthritis and osteoarthritis synovial tissue. 5-Lipoxygenase (5-LO) and 15-LO-1 enzymes are present in both rheumatoid arthritis (RA) and osteoarthritis (OA) synovial tissue. Photographs illustrating brown (diaminobenzidine) immunoperoxidase staining for $(a, b, c)$ 5-LO and (d, e, f) 15-LO-1 in sections from frozen synovial biopsies of (a, b, e) RA and (c, f) OA patients (hematoxylin counterstained). (d) Bronchial epithelium staining positive for 15-LO-1. Insets: (a) RA synovium stained with 5-LO antibody and (d) bronchial epithelium stained with 15LO-1 antibody, preabsorbed with purified 5-LO and 15-LO-1 protein, respectively. Original magnification: $\times 100$ (a, d and insets) and $\times 200(\mathrm{~b}, \mathrm{c}, \mathrm{e}$, f).

\section{Phenotype of cells expressing 5-LO and 15-LO in RA synovium}

We characterized the cellular distribution of the respective enzymes in RA synovial tissue. As shown by double immunofluorescence, 5-LO was mainly detected in synovial CD163+ macrophages (Figure $3 \mathrm{a}$ ) and in $\mathrm{CD}^{+} 8^{+}$macrophages (data not shown), but not in fibroblasts. 5-LO expression was also detected in scattered $\mathrm{CD} 66 \mathrm{~b}^{+}$neutrophils and tryptase-positive mast cells (Figure 3b,c). 15-LO-1-positive staining was identified in macrophages, fibroblasts and CD $31^{+}$endothelial cells (Figure 4). No staining was observed for either enzyme in $\mathrm{CD}^{+} \mathrm{T}$ cells or in $\mathrm{CD} 2 \mathrm{O}^{+} \mathrm{B}$ cells (data not shown).

\section{The clinical response after intraarticular GC administration is associated with a decrease in 5-LO expression but not in 15-LO-1 expression in rheumatoid synovium}

All patients included in the study were clinical responders as assessed by the arthroscopy-performing physician. Figure 5 demonstrates that intraarticular GCs significantly reduced the expression of 5 - $\mathrm{LO}$ enzyme in the synovium $(P=0.002)$. By contrast, the 15-LO-1 enzyme displayed a reduced expression after therapy in nine out of 11 patients, while two patients had a higher expression. Overall in this analysis, however, the 15LO-1 pattern did not significantly change following intraarticular corticosteroid therapy (Figure $5 \mathrm{~d}$ to $5 \mathrm{f}$ ).

\section{Synovial fluid cells express a functional 15-LO-1 enzyme and form 15-HETE}

RA synovial fluid cells demonstrated strong positive staining for 15-LO-1 in mononuclear cells and possibly in neutrophils (Figure 6a,b). Direct measurement of the 15-HETE content in synovial fluid obtained from RA patients was not possible, however, since the concentrations were below the limits of detection (data not shown). We therefore analyzed the functional ability of 15-LO-1 in cells isolated from RA synovial fluid. Flow cytometry analysis has shown that synovial fluid cells are composed mainly of neutrophils $(\sim 70 \%)$, monocytes and lymphocytes. The cellular composition of the synovial fluid samples is shown in Figure 6d.

After incubation of synovial fluid cells with or without $A A$ at $37^{\circ} \mathrm{C}$ for 5 minutes, 15 -HETE could be measured (mean \pm standard error of the mean $(n=5), 1.5 \pm 0.03 \mathrm{pmol} / 10^{6} \mathrm{cells}$ compared with $0.08 \pm 0.02 \mathrm{pmol} / 10^{6}$ cells in controls) (Figure $6 \mathrm{c})$. Any nonenzymatic $15-\mathrm{HETE}$ present in AA or formed dur- 
Figure 2

(a)

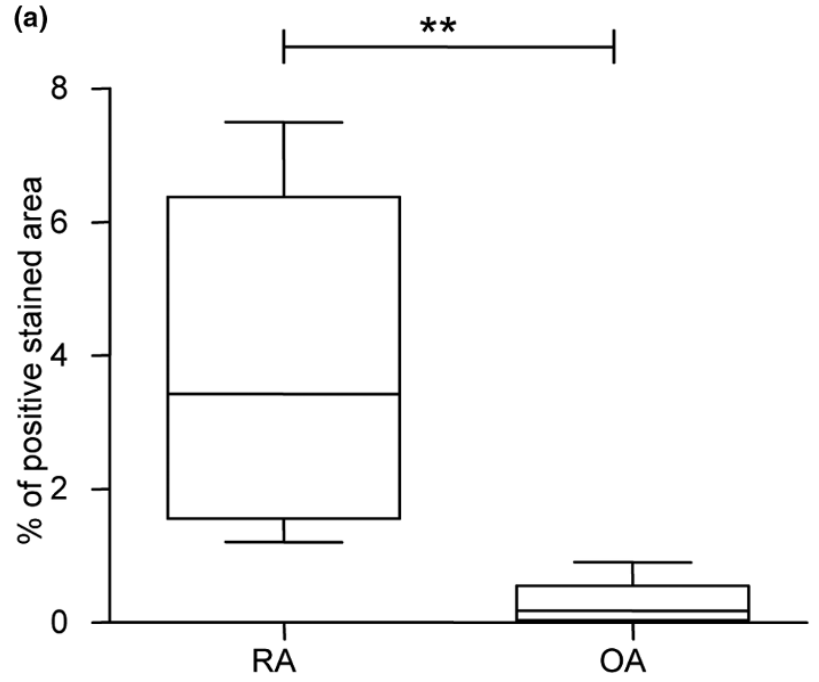

(b)

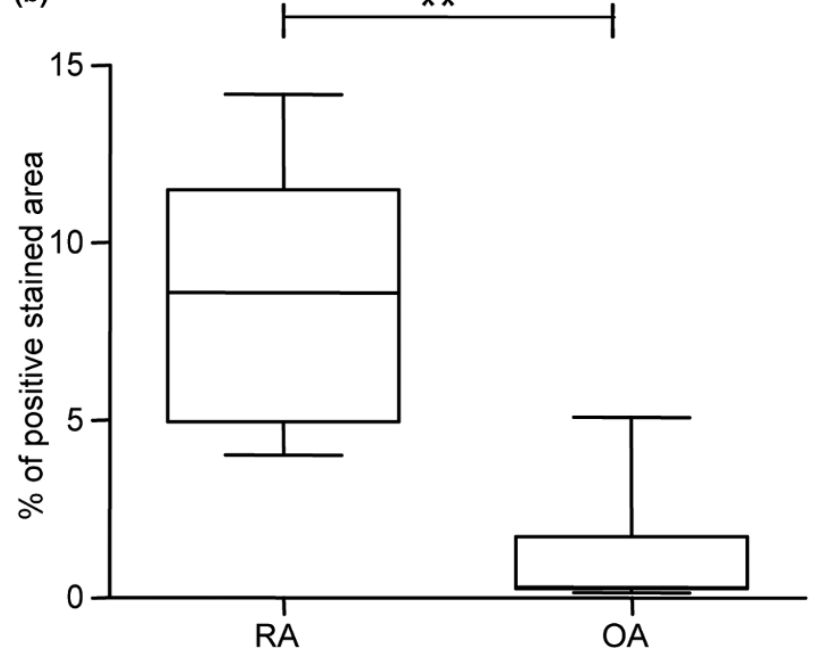

Osteoarthritis versus rheumatoid arthritis synovial expression of lipoxygenase enzymes. Ostheoarthritis (OA) synovial tissue displays a lower expression of 5-lipoxygenase (5-LO) and 15-LO-1 compared with rheumatoid arthritis (RA) synovium. Graphs show computer assisted-image analysis results for (a) 5-LO and (b) 15-LO-1 expression in RA tissue $(n=6)$ and OA tissue $(n=5)$. Results expressed as percentages of the total area of counterstained tissue. Horizontal lines, median values; whiskers, range values. ${ }^{\star \star} P<0.01$.

ing the incubation period in corresponding buffer controls was subtracted from these results.

\section{Discussion}

The leukotriene pathway, and in particular $\mathrm{LTB}_{4}$, has long been recognized to have deleterious effects in arthritis. Nevertheless, the enzymes responsible for arthritis formation have not been well characterized in synovial tissues, and nor is it known whether they are targeted by current RA therapy.

In the present study we showed that 5-LO is expressed in synovial tissue from patients with RA, mainly in macrophage-like cells and to a lesser extent in neutrophils and mast cells. We did not, however, detect 5-LO enzyme in T cells or B cells in RA biopsies. Although previous studies indicate that tonsillar $\mathrm{B}$ lymphocytes and B-cell lines are abundant in 5-LO protein $[39,40]$, recent data reveal that, within the tonsils, it is the mantle-zone $B$ cells that are 5-LO-positive and not the germinalcentre $B$ cells or plasma cells [41]. In fact, it has been suggested that RA synovial $B$ cells mainly represent mature activated memory $B$ cells and plasma cells [42]. Our findings that RA CD20+ $\mathrm{B}$ cells display no detectable 5-LO staining may therefore be explained in part by the specific B-cell subsets present in RA synovium. The wide expression of 5-LO in the synovial tissue of RA patients is in agreement with studies describing the $\mathrm{LTB}_{4}$ presence in RA synovial fluid [1] and the 5 -LO-positive immunostaining in areas coinciding with macrophage localization [24].

We also observed a low number of cells expressing 5-LO in OA tissue, scattered in areas with more abundant synovial membranes. By quantifying the positive staining areas, we showed that OA synovium expresses significantly less 5-LO than RA tissue. Indeed, OA synovial fluid has been shown to contain less $\mathrm{LTB}_{4}$ than RA fluid [8] and OA synovium is known to contain a low degree of infiltrating inflammatory cells, which is in line with our observations.

There are a limited number of studies investigating the 15-LO1 pathway in chronic inflammatory disorders, although the products of this pathway have long been recognized to play important roles in immune regulation and inflammation [43]. We underwent a detailed study characterizing the expression of 15-LO-1 enzyme in RA synovium, showing that it is highly expressed in synovial lining and scattered sublining fibroblast and macrophages and also in vessels of different sizes. In addition, we showed here that endothelial cells from both RA and OA biopsies express 15-LO-1. In OA, however, few synovial lining cells stained positively for 15-LO-1 while 15-LO-1 was abundantly present in vessels. The overall 15-LO expression was significantly lower in OA synovium compared with RA synovium.

The expression of functional 15-LO-1 in endothelial cells has been somewhat controversial, although some studies have demonstrated expression of 15-LO-1 in these cells [44]. Human and rabbit aortic endothelial cells, however, were more recently revealed to express 15-LO-1 mRNA and protein [45]. In addition, the presence of 15-LO-1 in endothelial cells was correlated with an induction of NF- $\mathrm{KB}$ activity and a subsequent increase in intracellular adhesion molecule expression [46], which may augment the local influx of cells. Our finding 
Figure 3
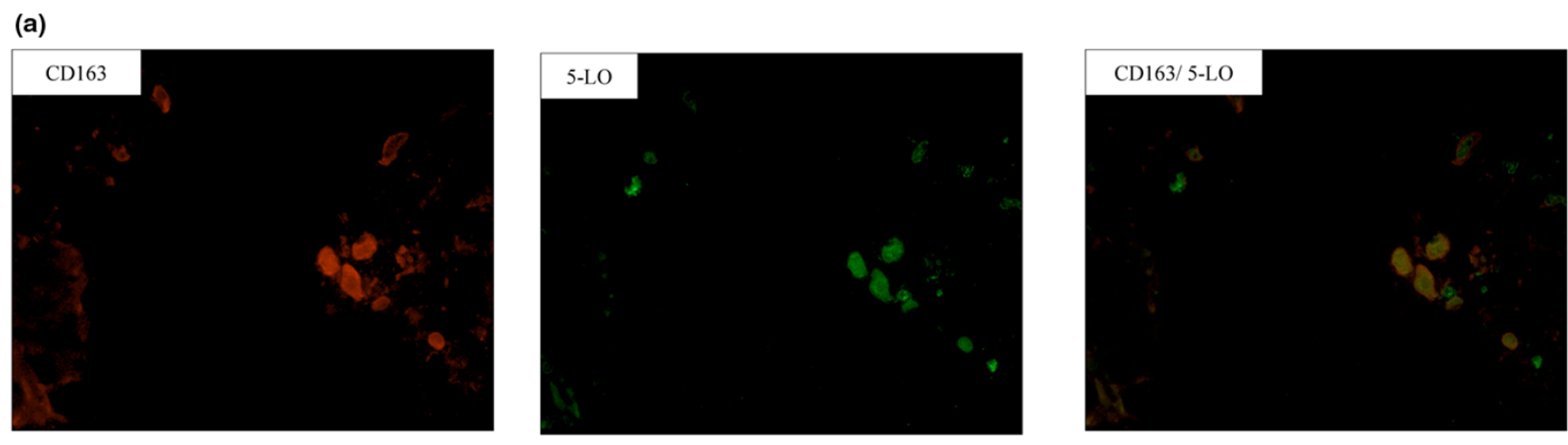

(b)
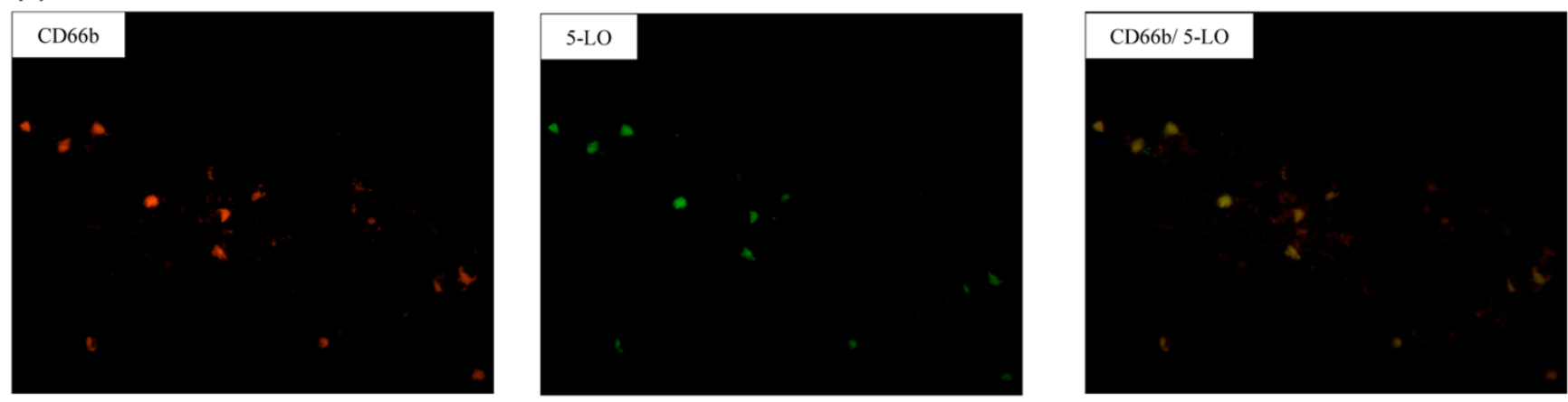

(c)
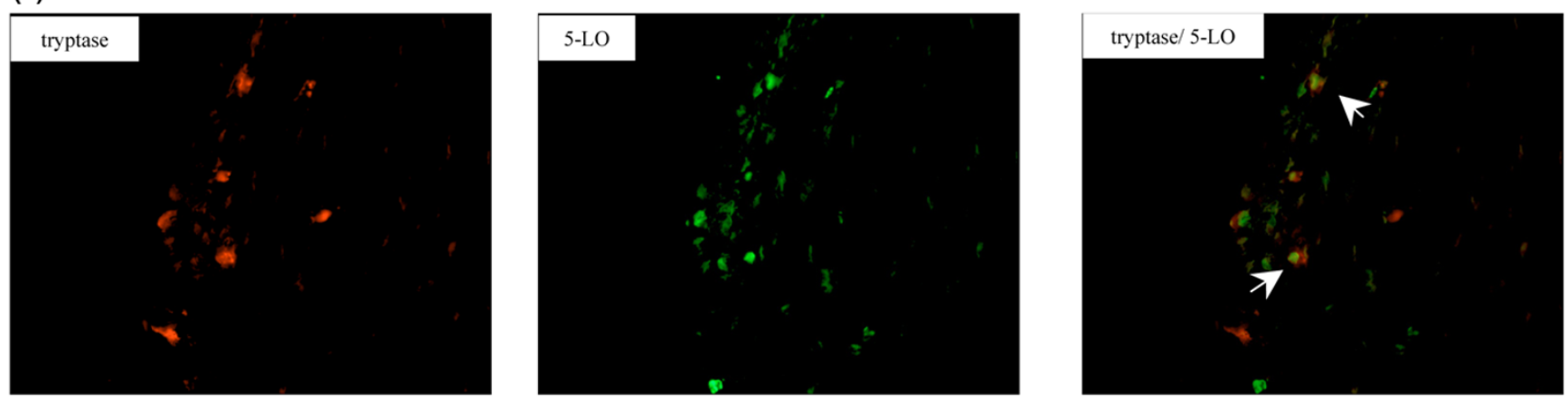

Synovial distribution pattern of 5-Lipoxygenase. CD163+ macrophages, CD66 b+ neutrophils and tryptase-positive mast cells express 5 -lipoxygenase (5-LO) in rheumatoid arthritis synovium. Photomicrographs showing fluorescent staining of (a) CD163+ cells, (b) CD66 b+ cells and (c) tryptase-positive cells (Alexa 546, red), 5-LO-positive cells (Alexa 488, green), and superimposed staining. White arrows, double-positive mast cells expressing 5-LO. Original magnification: $\times 400$.

that 15-LO-1 is localized in endothelial cells from RA synovium may therefore be related to its ability to form mediators that locally attract immune cells and promote inflammation.

Although 15-LO-1 is largely present in the synovial tissue, its main product (15-HETE) was not detectable in synovial fluid in the present study. Synovial fluid cells incubated with AA form only small amounts of this eicosanoid product. One explanation for this may reside in the methodology we used, such as a short incubation time. Furthermore, the synovial fluid was isolated from patients treated with various regimens. Cells incu- bated with AA still form significantly higher amounts of 15HETE compared with cells without $A A$, demonstrating the capacity of these cells to produce 15 -HETE.

We further demonstrated that 5-LO expression in synovial tissue was significantly decreased following intraarticular administration of GCs. This finding is consistent with previous work documenting reduced synthesis of $\mathrm{LTB}_{4}$ in neutrophils of patients with RA after intraarticular GC injection [33]. It has been demonstrated previously that the number of macrophages in RA synovial tissue is not influenced by therapy with 
Figure 4

(a)
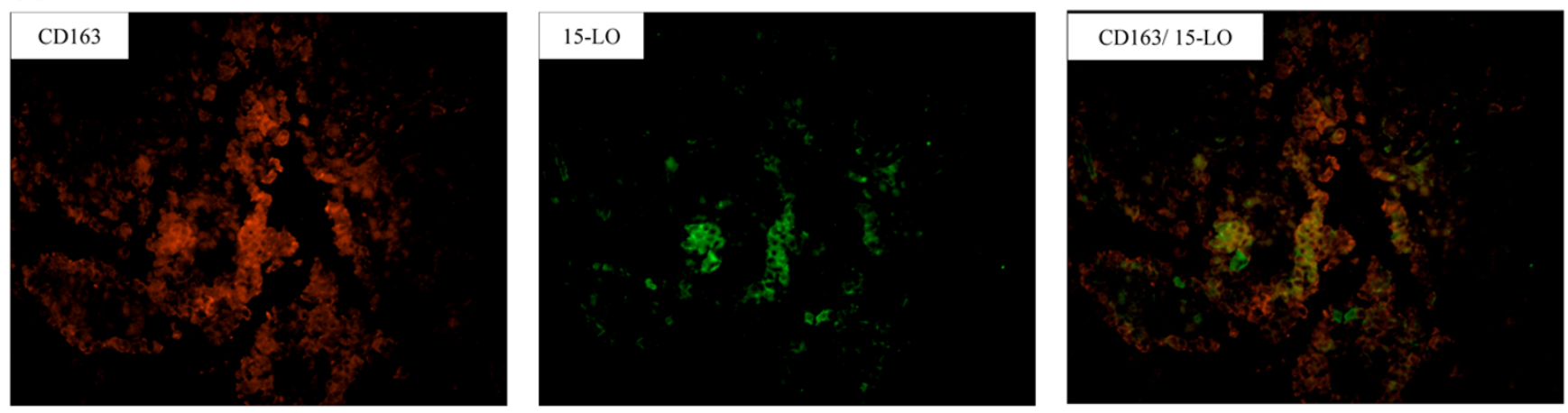

(b)
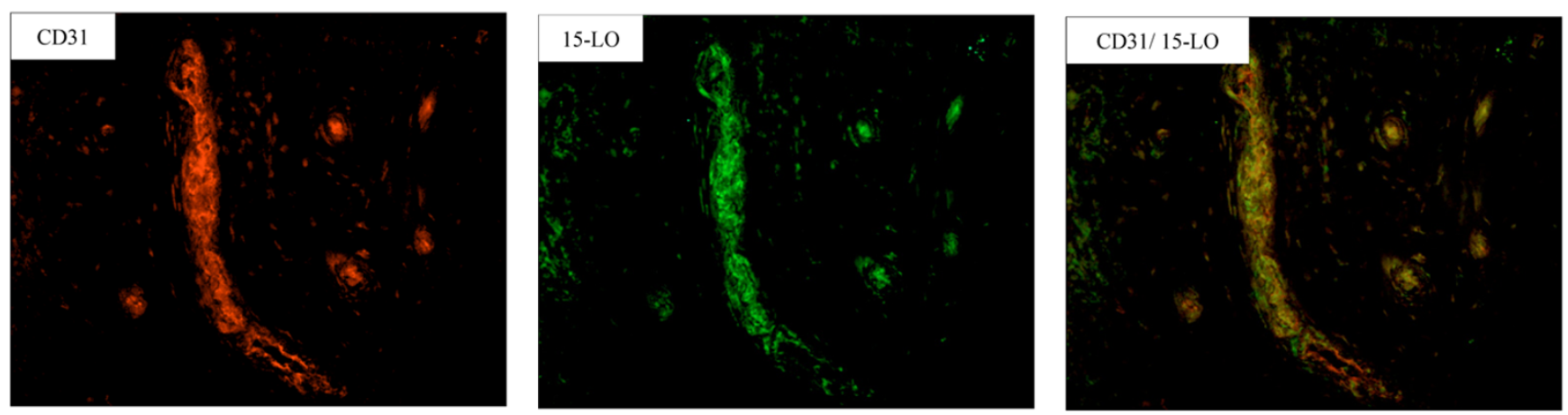

(c)
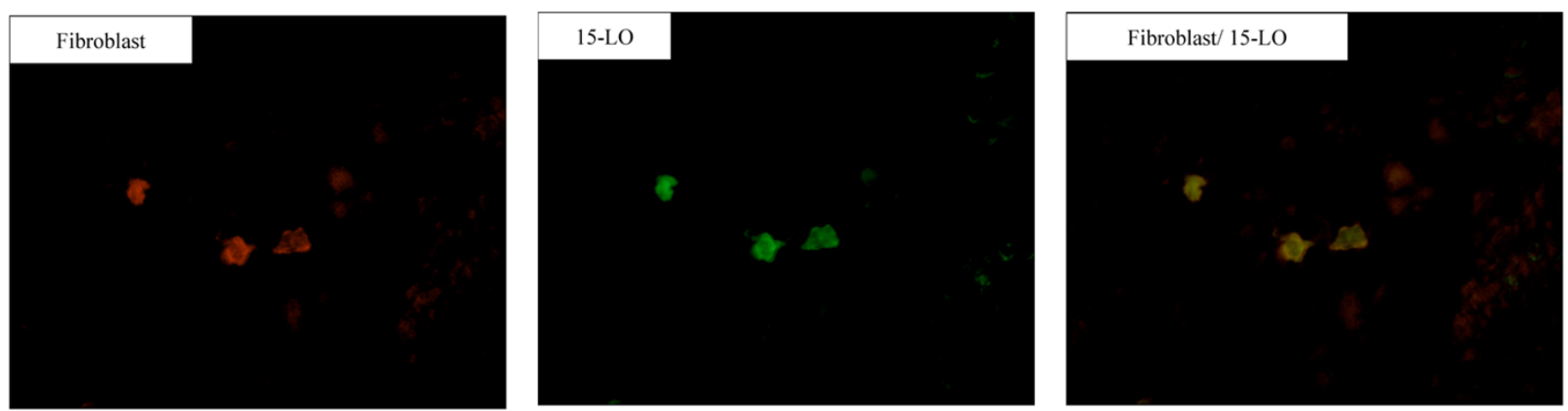

Synovial distribution pattern of 15-Lipoxygenase-1. CD163+ macrophages, CD31+endothelial cells and prolyl 4-hydrolase-positive fibroblast cells express 15-lipoxygenase-1 (15-LO-1) in rheumatoid arthritis synovium. Photomicrographs showing fluorescent staining of (a) CD163+ cells, (b) CD31+ cells and (c) prolyl 4-hydrolase-positive cells (Alexa 546, red), 15-LO-positive cells (Alexa 488, green), and superimposed stainings. Original magnification: $(a, b) \times 200$ and $(c) \times 400$.

local GCs [47]. This suggests that the decrease in 5-LO expression we observe here most probably reflects a decrease in cellular expression and not a lower number of cells locally present. Other investigators, however, have found that systemic treatment with GCs is followed by reduced macrophage infiltration in RA synovium [48]. Different biological mechanisms may operate when administrating GCs intraarticularly or systemically. Further investigation is therefore needed to elucidate the mechanism for the reduction in 5-LO expression.
GCs are very efficient in achieving important clinical and radiographic outcomes in RA [49]. Intraarticular GC may also confer a bone-protecting effect in RA by decreasing the RANKL/ osteoprotegerin ratio [50]. Previous studies have indicated $\mathrm{LTB}_{4}$ to be a negative regulator of bone metabolism by activating osteoclasts and inhibiting osteoblasts, thus promoting bone degradation and inhibiting bone formation [51,52]. In this context, the decrease in 5-LO expression after intraarticular GC therapy may indicate a potential role for 5-LO in bone degradation associated with inflammatory arthritis and sug- 
Before treatment

(a)

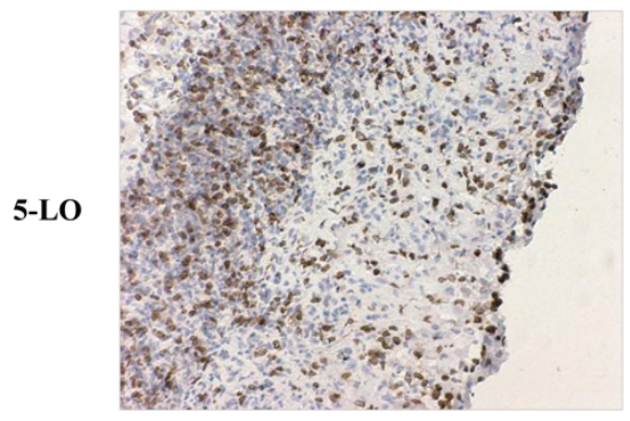

(d)

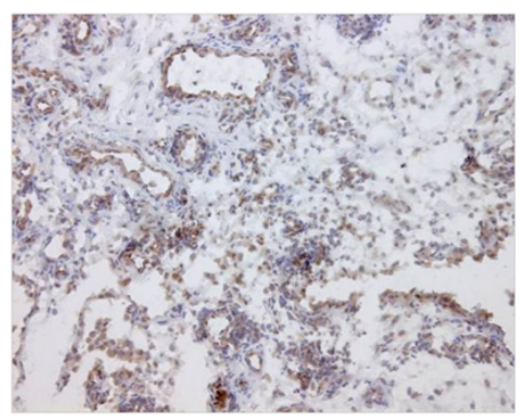

After treatment

(b)

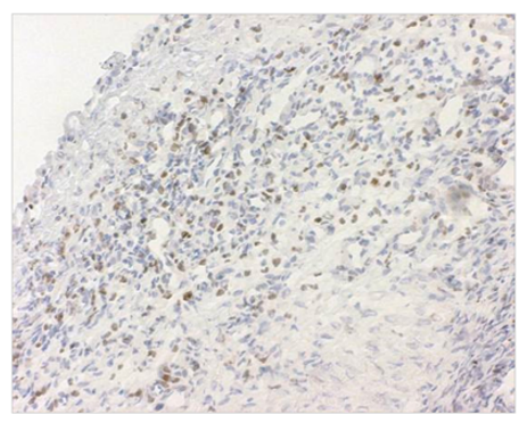

(e)

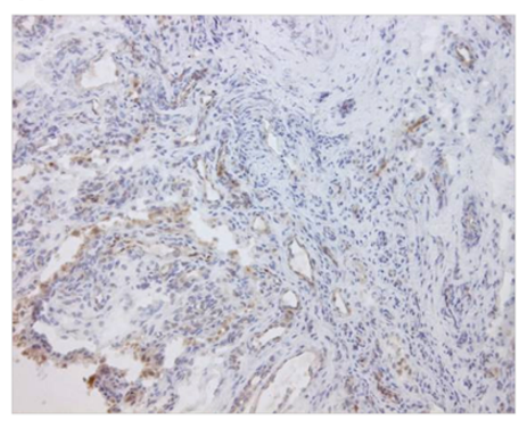

(c)

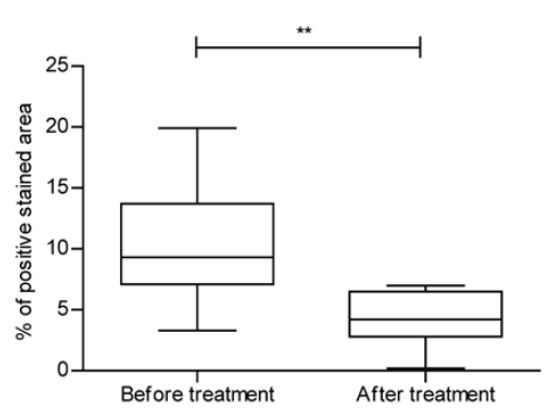

(f)

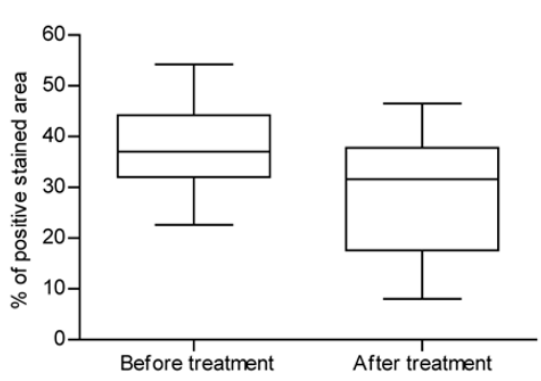

Intraarticular glucocorticoids effects on lipoxygenase expression in rheumatoid arthritis synovium. Intraarticular glucocorticoids decrease 5-lipoxygenase (5-LO) expression in rheumatoid arthritis (RA) synovium but leave unaltered the expression of 15-LO-1 enzyme. RA synovial tissue ( $n=11$ ) showing diaminobenzidine (brown) staining for 5-LO (a) before and (b) after treatment, and for 15-LO-1 (d) before and (e) after therapy (hematoxylin counterstained). Graphs show image analysis results for (c) 5-LO and (f) 15-LO-1 expression in synovial biopsy sections taken before and after intraarticular corticosteroid injection. Results expressed as percentage of the total area of counterstained tissue. Horizontal lines, median values; whiskers, range values. ${ }^{* \star} P<0.01$. Original magnification: $(\mathrm{a}, \mathrm{b}) \times 125$ and $(\mathrm{c}, \mathrm{d}) \times 160$.

gests a new mechanism for the bone-protecting effects of intraarticular GCs.

Since LTB4 has been demonstrated to be a key regulator in the pathogenesis of murine arthritis [9], it may be conceivable that targeting the 5-LO pathway could provide additional benefits in the treatment of RA, by reducing the formation of $\mathrm{LTB}_{4}$ and, by this means, decreasing the chemotaxis of inflammatory cells. Few studies have investigated the effects of 5-LO pathway inhibition in RA patients. In a 4-week clinical trial, treatment with zileuton showed a trend towards clinical improvement, but the duration of the study was not adequate to assess efficacy [53]. Novel 5-LO inhibitors may possibly offer better treatment effects.

There are few studies to date on 15-LO-1 in RA, and the role of its products in inflammation is not clearly defined. We demonstrate here that locally administered corticosteroids do not significantly change the expression of 15-LO-1 in RA synovium. Previously, it was shown that 15-LO-1 metabolites con- fer proinflammatory actions by increasing vascular permeability in vitro [19], enhancing expression of monocyte chemotactic protein-1 and TNF $\alpha$ in vascular smooth muscle cells via activation of NF-KB [54]. On the other hand, 15-LO-1 products may also have anti-inflammatory properties, by reducing synovitis through decreased $\mathrm{LTB}_{4}$ in experimental arthritis [55], inhibiting chemotaxis of neutrophils to LTB $_{4}$ [56] or through transcellular formation of lipoxins [57]. In this sense, it is noteworthy that IL-13, known to increase 15-LO-1 expression in several cell systems, is constantly present in synovial fluid of RA patients and has the ability to decrease proinflammatory cytokine production by synovial fluid mononuclear cells [58]. 15-LO-1 and its metabolites may therefore have dual roles in inflammation, and the net effect in RA needs further investigation.

\section{Conclusions}

In the present study we have shown that RA synovium expresses 5-LO and 15-LO-1, and that administration of intraarticular corticosteroids is followed by a significant reduc- 

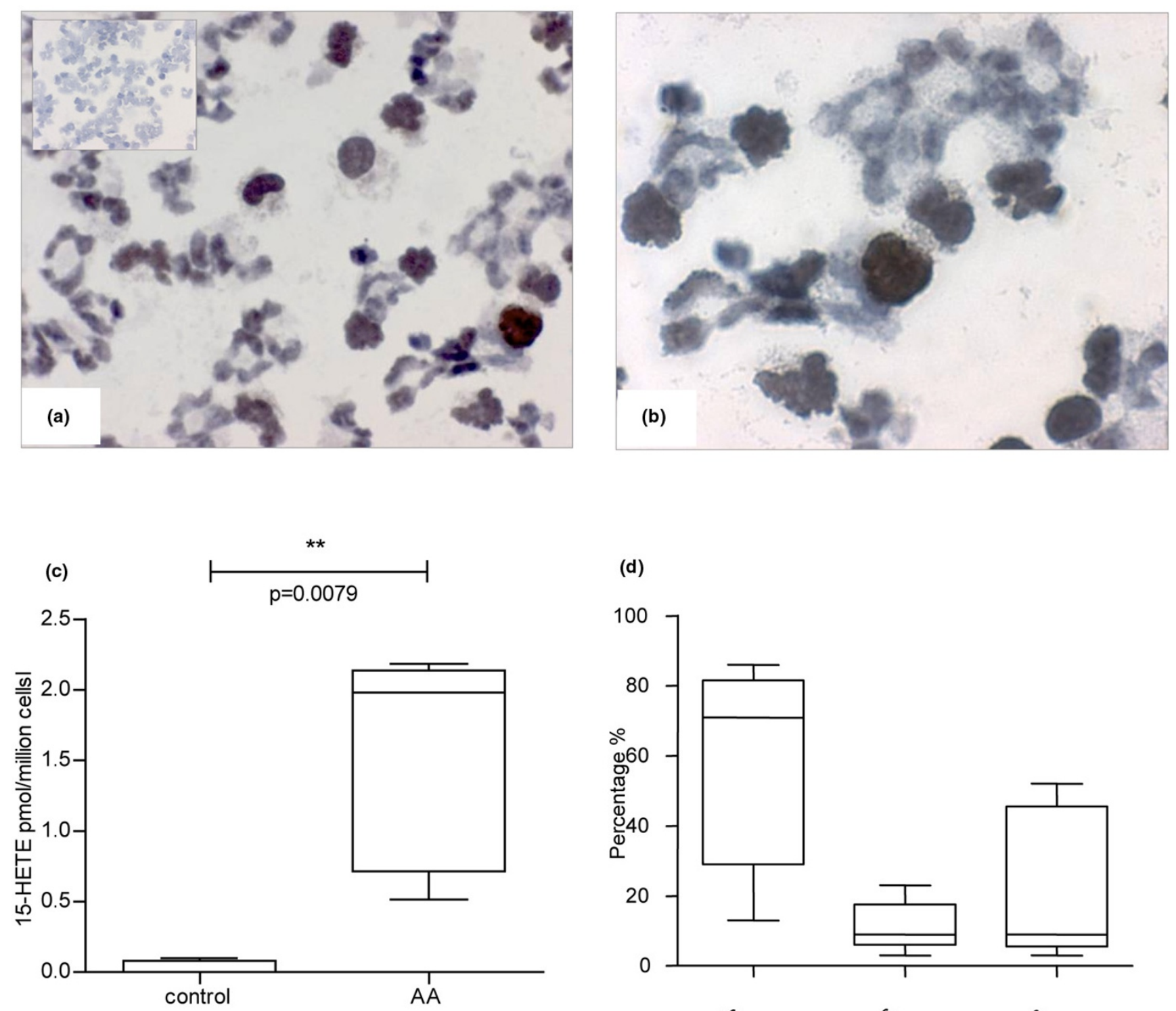

(d)

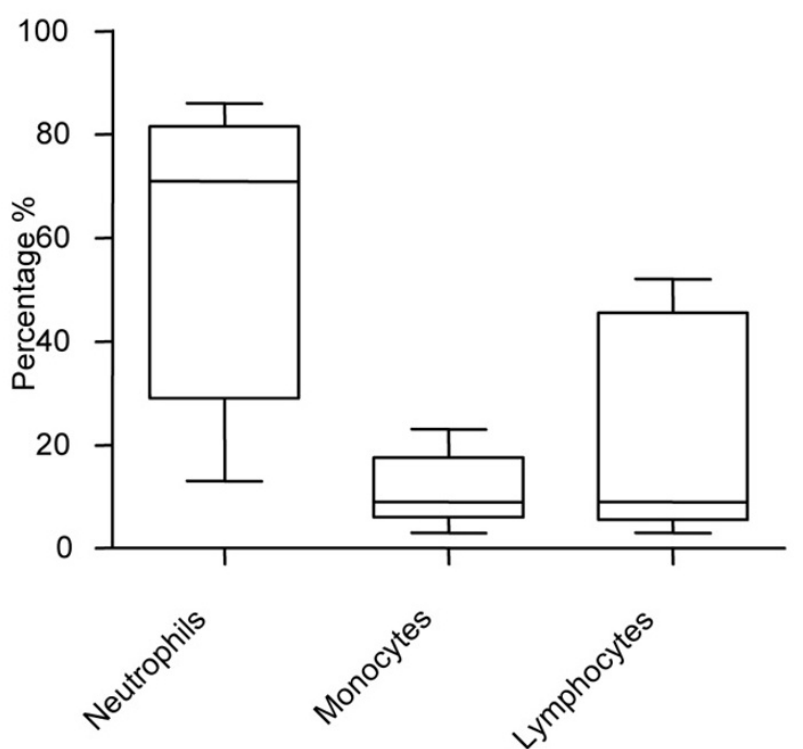

15-Lipoxygenase-1 expression in rheumatoid arthritis synovial fluid cells and 15-hydroxyeicosatetraenoic acid production. Rheumatoid arthritis (RA) synovial fluid cells express 15-lipoxygenase-1 (15-LO-1) and produce 15-hydroxyeicosatetraenoic acid (15-HETE) upon stimulation with arachidonic acid (AA). (a, b) Cytospin preparation of synovial fluid cells shows brown (diaminobenzidine) staining for 15-LO-1. Inset: isotype control. (c) 15HETE formation in control synovial fluid cells and synovial fluid cells incubated with AA. (d) Cellular composition of the RA synovial fluid showing the percentage of neutrophils, monocytes and lymphocytes in samples from five patients. Horizontal lines, median values; whiskers, range values. Original magnification: (a) $\times 500$ and (b) $\times 800$.

tion in 5-LO expression while leaving the 15-LO-1 enzyme unaffected. Our results provide an additional explanation for the beneficial effects of local corticosteroids in RA, through inhibition of 5-LO enzyme and reduced formation of its proinflammatory products. Together with previous studies incriminating $\mathrm{LTB}_{4}$ as a potent mediator of joint inflammation and destruction in RA, the present study suggests the use of 5-LO inhibitors as add-on therapy.

\section{Competing interests}

The authors declare that they have no competing interests. 


\section{Authors' contributions}

KRG performed acquisition and interpretation of data, performed statistical analysis and wrote the manuscript. MK participated in acquisition and interpretation of data, and in writing the manuscript. AIC provided the patient biopsies and their clinical data and participated in writing the manuscript. LB participated in the collection of data. EaK provided patient biopsies and participated in writing the manuscript. H-EC participated in the study design and preparation of the manuscript. OR participated in writing the manuscript. P-JJ was responsible for study design, interpretation of data and participated in writing the manuscript.

\section{Acknowledgements}

The authors thank Professor Lars Klareskog for valuable scientific advice and suggestions regarding planning of the study and writing the manuscript. The present work was supported by funds from Karolinska Institutet, the Swedish Research Council, The Swedish County Council, The Swedish Rheumatism Association, The Swedish Medical Society and the King Gustaf V 80-year fund.

\section{References}

1. Davidson EM, Rae SA, Smith MJ: Leukotriene B4, a mediator of inflammation present in synovial fluid in rheumatoid arthritis. Ann Rheum Dis 1983, 42:677-679.

2. Henderson WR Jr: The role of leukotrienes in inflammation. Ann Intern Med 1994, 121:684-697.

3. Lewis RA, Austen KF, Soberman RJ: Leukotrienes and other products of the 5-lipoxygenase pathway. Biochemistry and relation to pathobiology in human diseases. $N$ Engl J Med 1990, 323:645-655

4. Pillinger $\mathrm{MH}$, Abramson SB: The neutrophil in rheumatoid arthritis. Rheum Dis Clin North Am 1995, 21:691-714.

5. Ahluwalia N, Lin AY, Tager AM, Pruitt IE, Anderson TJ, Kristo F, Shen D, Cruz AR, Aikawa M, Luster AD, Gerszten RE: Inhibited aortic aneurysm formation in BLT1-deficient mice. J Immunol 2007, 179:691-697.

6. Leppert D, Hauser SL, Kishiyama JL, An S, Zeng L, Goetzl EJ: Stimulation of matrix metalloproteinase-dependent migration of T cells by eicosanoids. Faseb J 1995, 9:1473-1481.

7. Gursel T, Firat S, Ercan ZS: Increased serum leukotriene B4 level in the active stage of rheumatoid arthritis in children. Prostaglandins Leukot Essent Fatty Acids 1997, 56:205-207.

8. Ahmadzadeh N, Shingu M, Nobunaga M, Tawara T: Relationship between leukotriene B4 and immunological parameters in rheumatoid synovial fluids. Inflammation 1991, 15:497-503.

9. Chen M, Lam BK, Kanaoka Y, Nigrovic PA, Audoly LP, Austen KF, Lee DM: Neutrophil-derived leukotriene B4 is required for inflammatory arthritis. J Exp Med 2006, 203:837-842.

10. Andersson E, Schain F, Svedling M, Claesson HE, Forsell PK: Interaction of human 15-lipoxygenase-1 with phosphatidylinositol bisphosphates results in increased enzyme activity. Biochim Biophys Acta 2006, 1761:1498-1505.

11. Profita $M$, Sala A, Riccobono L, Paterno A, Mirabella A, Bonanno A, Guerrera D, Pace E, Bonsignore G, Bousquet J, Vignola AM: 15-Lipoxygenase expression and 15(S)-hydroxyeicoisatetraenoic acid release and reincorporation in induced sputum of asthmatic subjects. J Allergy Clin Immunol 2000, 105:711-716.

12. Deleuran $B$, Iversen $L$, Deleuran $M$, Yssel H, Kragballe $K$, Stengaard-Pedersen K, Thestrup-Pedersen K: Interleukin 13 suppresses cytokine production and stimulates the production of 15-HETE in PBMC. A comparison between IL-4 and IL-13. Cytokine 1995, 7:319-324.

13. Nassar GM, Morrow JD, Roberts LJ 2nd, Lakkis FG, Badr KF: Induction of 15-lipoxygenase by interleukin-13 in human blood monocytes. J Biol Chem 1994, 269:27631-27634.

14. Conrad DJ, Kuhn H, Mulkins M, Highland E, Sigal E: Specific inflammatory cytokines regulate the expression of human monocyte 15-lipoxygenase. Proc Natl Acad Sci USA 1992, 89:217-221.

15. Spanbroek R, Hildner M, Kohler A, Muller A, Zintl F, Kuhn H, Radmark O, Samuelsson B, Habenicht AJ: IL-4 determines eicosanoid formation in dendritic cells by down-regulation of 5 lipoxygenase and up-regulation of 15-lipoxygenase 1 expression. Proc Natl Acad Sci USA 2001, 98:5152-5157.

16. Levy BD, Romano M, Chapman HA, Reilly JJ, Drazen J, Serhan CN: Human alveolar macrophages have 15-lipoxygenase and generate 15(S)-hydroxy-5,8,11-cis-13-trans-eicosatetraenoic acid and lipoxins. J Clin Invest 1993, 92:1572-1579.

17. Gulliksson $M$, Brunnstrom $A$, Johannesson $M, B$ ackman $L$, Nilsson G, Harvima I, Dahlen B, Kumlin M, Claesson HE: Expression of 15-lipoxygenase type-1 in human mast cells. Biochim Biophys Acta 2007, 1771:1156-1165.

18. Harada S, Sugiyama E, Takebe S, Taki H, Shinoda K, Mohamed SG, Maruyama M, Hamazaki T, Kobayashi M: Cooperative induction of 15-lipoxygenase in rheumatoid synovial cells by IL-4 and proinflammatory cytokines. Clin Exp Rheumatol 2003, 21:753-758.

19. Feltenmark S, Gautam N, Brunnstrom A, Griffiths W, Backman L, Edenius C, Lindbom L, Bjorkholm M, Claesson HE: Eoxins are proinflammatory arachidonic acid metabolites produced via the 15-lipoxygenase-1 pathway in human eosinophils and mast cells. Proc Natl Acad Sci USA 2008, 105:680-685.

20. Serhan CN: Lipoxins and aspirin-triggered 15-epi-lipoxins are the first lipid mediators of endogenous anti-inflammation and resolution. Prostaglandins Leukot Essent Fatty Acids 2005, 73:141-162.

21. Serhan CN, Jain A, Marleau S, Clish C, Kantarci A, Behbehani B, Colgan SP, Stahl GL, Merched A, Petasis NA, Chan L, Van Dyke TE: Reduced inflammation and tissue damage in transgenic rabbits overexpressing 15-lipoxygenase and endogenous anti-inflammatory lipid mediators. J Immunol 2003, 171:6856-6865.

22. Wittwer J, Hersberger M: The two faces of the 15-lipoxygenase in atherosclerosis. Prostaglandins Leukot Essent Fatty Acids 2007, 77:67-77.

23. Liagre B, Vergne $P$, Rigaud M, Beneytout JL: Arachidonate 15lipoxygenase of reticulocyte-type in human rheumatoid arthritis type B synoviocytes and modulation of its activity by proinflammatory cytokines. J Rheumatol 1999, 26:1044-1051.

24. Hashimoto A, Hayashi I, Murakami $Y$, Sato $Y$, Kitasato H, Matsushita R, lizuka N, Urabe K, Itoman M, Hirohata S, Endo H: Antiinflammatory mediator lipoxin A4 and its receptor in synovitis of patients with rheumatoid arthritis. J Rheumatol 2007, 34:2144-2153.

25. Barnes PJ: Corticosteroids: the drugs to beat. Eur J Pharmacol 2006, 533:2-14.

26. Peters-Golden $M$, Thebert P: Inhibition by methylprednisolone of zymosan-induced leukotriene synthesis in alveolar macrophages. Am Rev Respir Dis 1987, 135:1020-1026.

27. Fuller RW, Kelsey CR, Cole PJ, Dollery CT, MacDermot J: Dexamethasone inhibits the production of thromboxane B2 and leukotriene B4 by human alveolar and peritoneal macrophages in culture. Clin Sci (Lond) 1984, 67:653-656.

28. Sebaldt RJ, Sheller JR, Oates JA, Roberts LJ 2nd, FitzGerald GA: Inhibition of eicosanoid biosynthesis by glucocorticoids in humans. Proc Natl Acad Sci USA 1990, 87:6974-6978.

29. Freeland HS, Pipkorn U, Schleimer RP, Bascom R, Lichtenstein LM, Naclerio RM, Peters SP: Leukotriene B4 as a mediator of early and late reactions to antigen in humans: the effect of systemic glucocorticoid treatment in vivo. J Allergy Clin Immunol 1989, 83:634-642.

30. Riddick CA, Ring WL, Baker JR, Hodulik CR, Bigby TD: Dexamethasone increases expression of 5-lipoxygenase and its activating protein in human monocytes and THP-1 cells. Eur $J$ Biochem 1997, 246:112-118.

31. Colamorea T, Di Paola R, Macchia F, Guerrese MC, Tursi A, Butterfield JH, Caiaffa MF, Haeggstrom JZ, Macchia L: 5-Lipoxygenase upregulation by dexamethasone in human mast cells. Biochem Biophys Res Commun 1999, 265:617-624.

32. Thomas E, Leroux JL, Blotman F, Descomps B, Chavis C: Enhancement of leukotriene A4 biosynthesis in neutrophils from patients with rheumatoid arthritis after a single glucocorticoid dose. Biochem Pharmacol 1995, 49:243-248. 
33. Klickstein LB, Shapleigh C, Goetzl EJ: Lipoxygenation of arachidonic acid as a source of polymorphonuclear leukocyte chemotactic factors in synovial fluid and tissue in rheumatoid arthritis and spondyloarthritis. J Clin Invest 1980, 66:1166-1170

34. Makheja AN, Bloom S, Muesing R, Simon T, Bailey JM: Antiinflammatory drugs in experimental atherosclerosis. 7. Spontaneous atherosclerosis in WHHL rabbits and inhibition by cortisone acetate. Atherosclerosis 1989, 76:155-161.

35. Laprise C, Sladek R, Ponton A, Bernier MC, Hudson TJ, Laviolette $M$ : Functional classes of bronchial mucosa genes that are differentially expressed in asthma. BMC Genomics 2004, 5:21.

36. Arnett FC, Edworthy SM, Bloch DA, McShane DJ, Fries JF, Cooper NS, Healey LA, Kaplan SR, Liang MH, Luthra HS, Medsger TA Jr, Mitchell DM, Neustadt DH, Pinals RS, Schaller JG, Sharp JT, Wilder RL, Hunder GG: The American Rheumatism Association 1987 revised criteria for the classification of rheumatoid arthritis. Arthritis Rheum 1988, 31:315-324.

37. Ulfgren AK, Lindblad S, Klareskog L, Andersson J, Andersson U: Detection of cytokine producing cells in the synovial membrane from patients with rheumatoid arthritis. Ann Rheum Dis 1995, 54:654-661.

38. Westman M, Korotkova M, af Klint E, Stark A, Audoly LP, Klareskog L, Ulfgren AK, Jakobsson PJ: Expression of microsomal prostaglandin E synthase 1 in rheumatoid arthritis synovium. Arthritis Rheum 2004, 50:1774-1780.

39. Werz O, Tretiakova I, Michel A, Ulke-Lemee A, Hornig M, Franke L, Schneider G, Samuelsson B, Radmark O, Steinhilber D: Caspasemediated degradation of human 5-lipoxygenase in B lymphocytic cells. Proc Natl Acad Sci USA 2005, 102:13164-13169.

40. Jakobsson PJ, Odlander B, Steinhilber D, Rosen A, Claesson HE: Human B lymphocytes possess 5-lipoxygenase activity and convert arachidonic acid to leukotriene B4. Biochem Biophys Res Commun 1991, 178:302-308.

41. Mahshid Y, Lisy MR, Wang X, Spanbroek R, Flygare J, Christensson B, Bjorkholm M, Sander B, Habenicht AJ, Claesson HE: High expression of 5-lipoxygenase in normal and malignant mantle zone B lymphocytes. BMC Immunol 2009, 10:2.

42. Cantaert T, Kolln J, Timmer T, Pouw Kraan TC van der, Vandooren $\mathrm{B}$, Thurlings RM, Canete JD, Catrina Al, Out T, Verweij CL, Zhang Y, Tak PP, Baeten D: B lymphocyte autoimmunity in rheumatoid synovitis is independent of ectopic lymphoid neogenesis. $\mathrm{J}$ Immuno/ 2008, 181:785-794.

43. Kuhn $\mathrm{H}, \mathrm{O}$ 'Donnell VB: Inflammation and immune regulation by 12/15-lipoxygenases. Prog Lipid Res 2006, 45:334-356.

44. Lee YW, Kuhn H, Kaiser S, Hennig B, Daugherty A, Toborek M: Interleukin 4 induces transcription of the 15-lipoxygenase I gene in human endothelial cells. J Lipid Res 2001, 42:783-791.

45. Tang X, Holmes BB, Nithipatikom K, Hillard CJ, Kuhn H, Campbell WB: Reticulocyte 15-lipoxygenase-l is important in acetylcholine-induced endothelium-dependent vasorelaxation in rabbit aorta. Arterioscler Thromb Vasc Biol 2006, 26:78-84.

46. Bolick DT Orr AW, Whetzel A, Srinivasan S, Hatley ME, Schwartz MA, Hedrick CC: 12/15-Lipoxygenase regulates intercellular adhesion molecule-1 expression and monocyte adhesion to endothelium through activation of RhoA and nuclear factorкB. Arterioscler Thromb Vasc Biol 2005, 25:2301-2307.

47. af Klint E, Grundtman C, Engstrom M, Catrina Al, Makrygiannakis D, Klareskog L, Andersson U, Ulfgren AK: Intraarticular glucocorticoid treatment reduces inflammation in synovial cell infiltrations more efficiently than in synovial blood vessels. Arthritis Rheum 2005, 52:3880-3889.

48. Gerlag DM, Haringman JJ, Smeets TJ, Zwinderman AH, Kraan MC, Laud PJ, Morgan S, Nash AF, Tak PP: Effects of oral prednisolone on biomarkers in synovial tissue and clinical improvement in rheumatoid arthritis. Arthritis Rheum 2004, 50:3783-3791.

49. Harris ED Jr: Prednisolone in early rheumatoid arthritis: an antiinvasive effect. Arthritis Rheum 2005, 52:3324-3325.

50. Makrygiannakis D, af Klint E, Catrina SB, Botusan IR, Klareskog E, Klareskog L, Ulfgren AK, Catrina Al: Intraarticular corticosteroids decrease synovial RANKL expression in inflammatory arthritis. Arthritis Rheum 2006, 54:1463-1472.

51. Garcia C, Boyce BF, Gilles J, Dallas M, Qiao M, Mundy GR, Bonewald LF: Leukotriene B4 stimulates osteoclastic bone resorp- tion both in vitro and in vivo. J Bone Miner Res 1996, 11:1619-1627.

52. Traianedes K, Dallas MR, Garrett IR, Mundy GR, Bonewald LF: 5Lipoxygenase metabolites inhibit bone formation in vitro. Endocrinology 1998, 139:3178-3184.

53. Weinblatt ME, Kremer JM, Coblyn JS, Helfgott S, Maier AL, Petrillo G, Henson B, Rubin P, Sperling R: Zileuton, a 5-lipoxygenase inhibitor in rheumatoid arthritis. J Rheumatol 1992, 19:1537-1541.

54. Dwarakanath RS, Sahar S, Reddy MA, Castanotto D, Rossi JJ, Natarajan R: Regulation of monocyte chemoattractant protein1 by the oxidized lipid, 13-hydroperoxyoctadecadienoic acid, in vascular smooth muscle cells via nuclear factor-kappa B (NF-KB). J Mol Cell Cardiol 2004, 36:585-595.

55. Hansen ES, Fogh K, Hjortdal VE, Henriksen TB, Noer I, Ewald H, Herlin T, Kragballe K, Bunger C: Synovitis reduced by inhibition of leukotriene B4. Carrageenan-induced gonarthritis studied in dogs. Acta Orthop Scand 1990, 61:207-212.

56. Fogh K, Hansen ES, Herlin T, Knudsen V, Henriksen TB, Ewald H, Bunger $C$, Kragballe K: 15-Hydroxy-eicosatetraenoic acid (15HETE) inhibits carrageenan-induced experimental arthritis and reduces synovial fluid leukotriene B4 (LTB4). Prostaglandins 1989, 37:213-228.

57. Yacoubian S, Serhan CN: New endogenous anti-inflammatory and proresolving lipid mediators: implications for rheumatic diseases. Nat Clin Pract Rheumatol 2007, 3:570-579.

58. Isomaki $P$, Luukkainen $R$, Toivanen $P$, Punnonen J: The presence of interleukin-13 in rheumatoid synovium and its antiinflammatory effects on synovial fluid macrophages from patients with rheumatoid arthritis. Arthritis Rheum 1996, 39:1693-1702. 